\title{
Molecular Forms of Lactoferrin in Stool and Urine from Infants Fed Human Milk
}

\author{
ARMOND S. GOLDMAN, CUTBERTO GARZA, RICHARD J. SCHANLER, AND \\ RANDALL M. GOLDBLUM
}

\begin{abstract}
Department of Pediatrics, Human Biological Chemistry and Genetics, and Microbiology, The University of Texas Medical Branch, Galveston, Texas 77550 [A.S.G., R.M.G.]; Division of Nutritional Sciences, Cornell University, Ithaca, New York 14853 [C.G.J; and The Department of Pediatrics, Baylor College of Medicine and the U.S. Department of Agriculture, Children's Nutrition Research Center, Houston, Texas 77030 [R.J.S.]
\end{abstract}

\begin{abstract}
The molecular forms of lactoferrin (LF) were examined in stools and urine collected at 2.5 or 5 wk of age from very low birth wt infants fed either a cow's milk formula or a fortified human milk preparation. LF was not found by Western blotting in excreta from infants fed cow's milk. In contrast, intact and fragmented forms of IF were detected in stools and concentrated urine of each infant who received human milk. Only intact LF was detected in the fortified human milk preparation, whereas many types of LF fragments were present in the stools and urine. The approximate molecular wt of the most prominent fragments were 44, 38, 34, and $32 \mathrm{kD}$. However, the stools also displayed lower molecular wt fragments that were not found in urines of those infants. The LF fragments in those excreta were similar in size to those produced in vitro by limited digestion of apo-LF with trypsin. Furthermore, fragments produced by in vitro proteolysis were immunoreactive in an ELISA for LF. Thus, the fragments of LF in stools of very low birth wt infants fed human milk appeared to be produced by in vivo proteolysis, and the close resemblance between the $L F$ fragments in the stools and urine suggests that the urinary LF fragments originated in the gastrointestinal tract. It remains unclear, however, whether the whole LF molecules that were fragmented were derived solely from ingested $L F$ in human milk $o x$ in part from LF produced by the infant in response to human milk feedings. (Pediatr Res 27: 252-255, 1990)
\end{abstract}

\section{Abbreviations}

LF, lactoferrin

VLBW, very low birth wt

CMF, cow's milk formula

FHM, fortified human milk

Recently, there has been an increased interest in the effects of human milk upon the immunologic status of the recipient infant. In addition to the direct protective effects of immunologic factors in the recipient's gastrointestinal tract $(1,2)$, certain studies suggest that some defense agents in the milk may be absorbed from the gastrointestinal tract or that other agents in human milk may speed the development of the mucosal defense system

Received March 28, 1989; accepted October 13, 1989

Correspondence Armond S. Goldman, M.D., The University of Texas Medical Branch, Department of Pediatrics, Division of Immunology/Allergy, Room C2-35 Child Health Center, Galveston, TX 77550.

Supported by Contracts N01 HD 22814 and N01 HD 62918 from the National Institute of Child Health and Human Development and Grant R01 Al 21412-04 from the National Institute of Allergy and Infectious Diseases. of the infant (3-12). Recent studies demonstrate that the urinary excretion of IgA $(11,12)$, total secretory component $(12)$, and LF (12) was greater in human milk as compared to cow's milkfed infants. Those findings were particularly germane because urine is a secretion whose formation is far removed from direct contact with ingested human milk. In one report (12), preliminary evidence was presented that several fragments, as well as intact LF, were excreted in the urine of VLBW infants who were fed human milk. In this investigation, we sought to ascertain whether these molecular fragments of LF in the urine of those VLBW infants originated in the gastrointestinal tract. Therefore, we examined stools as well as urine for these fragments from VLBW infants fed human milk. In addition, we attempted to determine whether the fragments may contribute to the quantitative measurement of LF in those excreta, and whether the fragments are created by the action of certain enzymes found in the digestive tract.

\section{MATERIALS AND METHODS}

Study design. The study was approved by the institutional review boards of both institutions. Two groups of VLBW infants from the same hospital population were investigated $(12,13)$. One infant received CMF (Similac PM $60 / 40$ or Similac 24, Ross Laboratories, Columbus, $\mathrm{OH}$ ) and the second received FHM prepared daily by adding pasteurized, lyophilized mature donor milk to fresh maternal milk as previously described (12, 13). The two groups were similar in respect to gestational age in wk (mean $\pm \mathrm{SD}, \mathrm{CMF}, 29 \pm 1$; FHM, $29 \pm 1$ ); birth wt in $\mathrm{g}$ (CMF, $1201 \pm 78$; FHM, $1175 \pm 146$ ), average total milk intake in $\mathrm{g} / \mathrm{kg} / \mathrm{d}(\mathrm{CMF}, 143 \pm 9 ; \mathrm{FHM}, 145 \pm 7)$, and total nitrogen intake in $\mathrm{mg} / \mathrm{kg} / \mathrm{d}(\mathrm{CMF}, 492 \pm 73$; FHM, $458 \pm 40)$. More details concerning the two groups and their feeding protocols have been reported previously $(12,13)$. Stools and urine were collected continuously during 96 -h balance periods at 2.5 and 5 wk of age and the specimens were stored at $-20^{\circ} \mathrm{C}$ until analyzed.

$S D S-P A G E-W e s t e r n$ blotting. The molecular sizes of LF in the FHM, stools, and urine from 15 infants fed CMF and 15 infants fed FHM were examined by Western blotting (14). The mol wt standards (Bethesda Research Laboratories Life Technologies, Inc., Gaithersburg, MD) in these experiments were myosin (200 $\mathrm{kD})$, phosphorylase B $(97 \mathrm{kD})$, BSA $(68 \mathrm{kD})$, ovalbumin (43 $\mathrm{kD})$, carbonic anhydrase $(27 \mathrm{kD}), \beta$-lactoglobulin $(18 \mathrm{kD})$, and lysozyme $(14 \mathrm{kD})$. The samples were separated on plates containing $10 \%$ polyacrylamide in a Tris-SDS buffer. The columns were $0.15 \mathrm{~cm}$ in thickness and $15 \mathrm{~cm}$ in length. Fifteen $\mu \mathrm{g}$ of human LF isolated from human milk (Sigma Chemical Co., St. Louis, MO), human milk samples diluted 1:10, stools diluted $1: 1$ or $1: 2$, and urine specimens concentrated 20 - to 30 -fold by 
Minicon 10 (Amicon, Danvers, MA) were mixed with equal volumes of the standard nonreducing SDS-sample buffer and boiled for $2 \mathrm{~min}$. The mixture $(100 \mu \mathrm{L})$ was applied to the gel well and electrophoresed for $1 \mathrm{~h}$ at $20 \mathrm{~mA}$ and then for $3 \mathrm{~h}$ at $30 \mathrm{~mA}$. The proteins in the gels were transferred electrophoretically to nitrocellulose sheets. The sheets were blocked with gelatin (3\%), treated with rabbit polyclonal antisera to human LF (1:250; Dako Corporation, Santa Barbara, CA), and incubated with goat antisera to rabbit IgG conjugated to horseradish peroxidase (1:1500; Bio-Rad, Chemical Division, Richmond, CA). After washing, bound enzyme was detected by applying chloronaphthol $(60 \mathrm{mg})$ in Tris saline buffer and hydrogen peroxide (100 $\mu \mathrm{L}$ of a $30 \%$ solution) in methyl alcohol $(20 \mathrm{~mL})$ to the sheets. The distances of migration of the protein standards were measured. Those measurements were logarithmically transformed to achieve a linear relationship between distance of migration and size of the mol wt standards and purified LF. The approximate molecular sizes of the LF fragments were estimated by plotting the log of the distance of migration of each fragment band on the standard graphs. As little as $3.2 \mathrm{ng} / \mu \mathrm{L}$ of purified apo- or diferric LF were detected by this method.

Fragments of human $L F$ produced in vitro. Apo-LF was produced by dialyzing human LF (Sigma, no. L-8010) first against an acetic acid/sodium acetate solution (pH 4) and then against water. OD readings obtained at $465 \mathrm{~nm}$ (Gilford Instrument Laboratories, Inc., Oberlin, $\mathrm{OH})$ or staining of Western blots with 3-(2-pyridyl)-5,6-bis (2-(5-furylsulfonic acid))-1,2,4 triazine disodium salt (Ferene S; Sigma) (15) revealed no bound iron. Diferric LF was produced by incubating human LF (Sigma) with $1 \mathrm{mM}$ of a ferric nitrilotriacetic acid complex and $1 \mathrm{M} \mathrm{NaHCO} 3$ overnight at $25^{\circ} \mathrm{C}$. Bound iron was detected in those preparations by spectrophotometry or staining with Ferene $S$.

Human apo-LF or diferric LF was partially digested with bovine pancreatic trypsin (Sigma, no. T-8128, 1050 BAEE U/ mg protein) or a mixture of porcine pancreatic trypsin and chymotrypsin (Sigma, no. T-8253, 10,000-13,000 BAEE U/mg protein). Enzyme to substrate ratios ranging from 1:10 to $1: 100$ were used. After a 4-h incubation, reactions were stopped with a soybean tryptic inhibitor (Sigma, no. T-9003; $1.0 \mathrm{mg}$ inhibits $1.25 \mathrm{mg}$ trypsin). LF fragments were then detected by Western blotting.

Detection of LF fragments by ELISA. Apo-LF treated with trypsin (Sigma, no. $T-8128$; substrate to enzyme ratio, 100:1) for $4 \mathrm{~h}$ at $37^{\circ} \mathrm{C}$ and then with the soybean trypsin inhibitor produced a preparation that contained six to eight fragments but no intact LF. The amount of immunoreactive LF in the trypsinized preparation was quantified by ELISA method and compared to equal amounts of purified LF $(4.0,1.0,0.25,0.06$, or $0.015 \mu \mathrm{g} / \mathrm{mL})$. The binding antibodies were polyclonal rabbit antibodies (Dako Corporation, Santa Barbara, CA; $3 \mu \mathrm{g} / \mathrm{mL}$ ) and the antibody detector was a peroxidase conjugated, affinity-purified rabbit antihuman LF (Accurate Chemical and Scientific Corporation, Westbury, NY; JZH-3515, 1:25,000). Negative controls consisted of trypsin per se or trypsin and antitrypsin, but no LF. As little as $0.7 \mathrm{ng}$ of purified apo-or diferric LF were detected by ELISA.

We also tested whether LF fragments could be detected in the presence of intact LF. Native LF $(2 \mu \mathrm{g} / \mathrm{mL})$ was mixed with apoLF $(2 \mu \mathrm{g} / \mathrm{mL})$ that had been treated with trypsin (substrate to enzyme ratio, 100:1). Five experiments were performed. In each case, the amounts of immunoreactive LF in the intact LF, trypsinized LF, or mixtures of native and trypsinized LF were measured by ELISA. The predicted final concentrations were calculated by adding the concentrations of intact LF $(2 \mu \mathrm{g} / \mathrm{mL})$ to the amount measured in the LF fragment preparations. These predicted values were then compared to the measurements of immunoreactive LF in the mixtures of apo-LF and trypsinized LF.

\section{RESULTS}

No human LF was detected in the CMF and only the native $(80 \mathrm{kD})$ form of LF was found in human milk preparations used in these feeding experiments (Fig. 1). No LF was detected by Western blotting in the excreta of the infants who were fed CMF, whereas both native and lower molecular forms of LF were detected in the stools and urines of each of the infants who received FHM (Figs. 1 and 2). As many as six to eight, and as few as three, fragments were detected in those excreta. The approximate molecular mass of the most prominent fragments
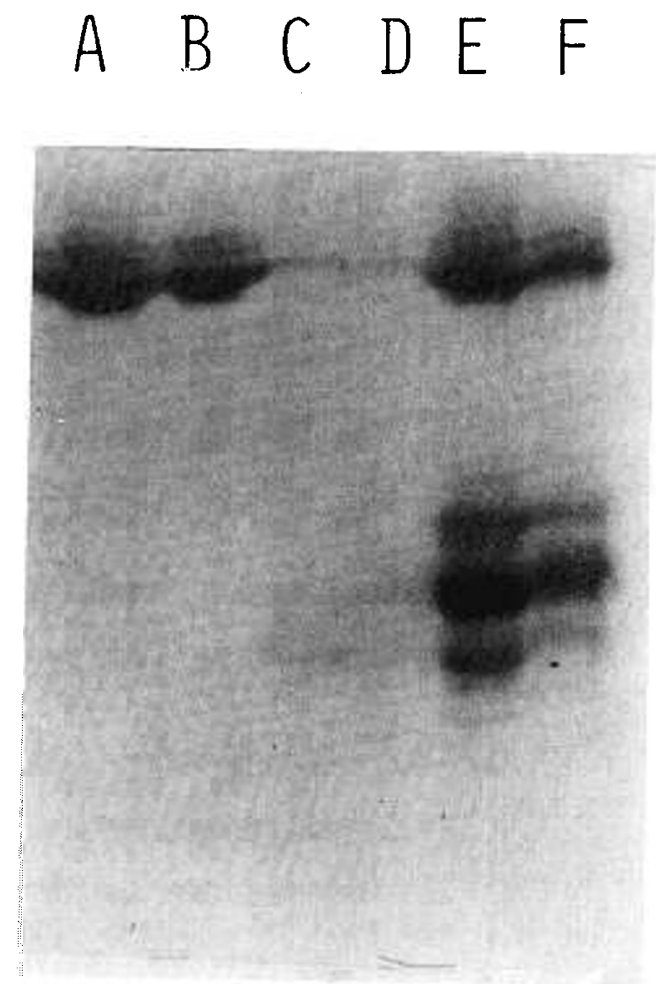

Fig. 1. Representative Western blotting of stools and urine for LF. The lanes are as follows: $A$, human LF; $B$, human milk; $C$, stool from an infant fed CMF; $D$, concentrated urine from a CMF-fed infant; $E$, stool from a FHM-fed infant; and $F$, concentrated urine from a FHM infant. Mol wt standards were also subjected to Western blotting but were not included because of the low intensity of staining of the bands.

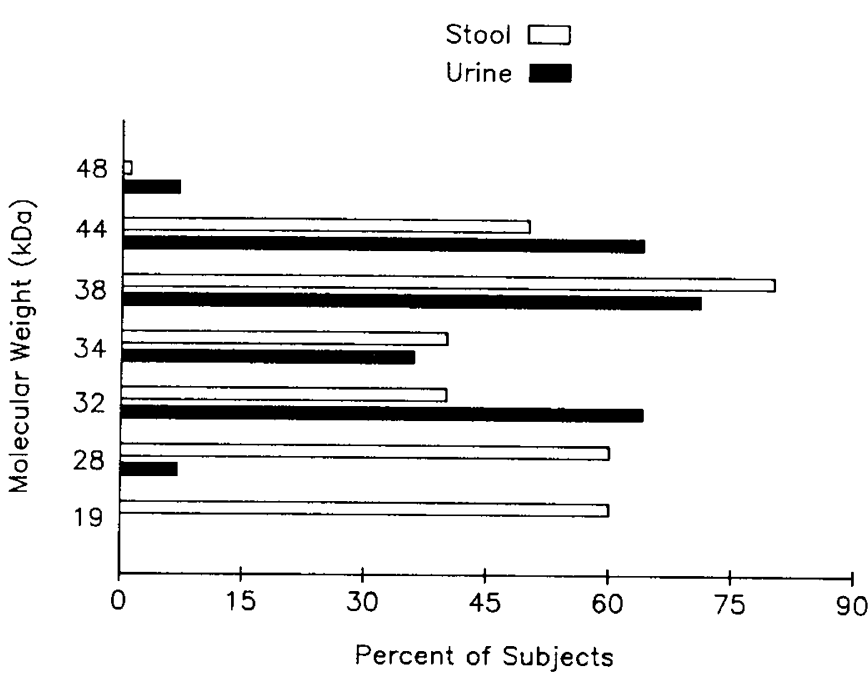

Fig. 2. The frequency of the types of LF fragments found in the stools ( $\square$ ) and concentrated urines ( $\square$ ) of VLBW infants fed FHM. All of the stools and urines from these subjects also contained the native ( 80 $k D)$ form of $L F$. 
were $44,38,34$, and $32 \mathrm{kD}$. The molecular moieties of LF in the stools and urine from the same infant were usually similar, although additional smaller fragments were often found in the stools (Fig. 2). No differences were found in the forms of LF in excreta obtained at 2.5 or $5 \mathrm{wk}$ of age.

The sizes of the LF fragments in the stools and urine from the infants fed FHM were similar to certain fragments generated by limited digestion of apo-LF with trypsin (Fig. 3). Similar fragments were produced by treating apo-LF with trypsin and chymotrypsin (results not shown), whereas only two major fragments corresponding to the C-lobes $(50 \mathrm{kD})$ and N-lobes $(30 \mathrm{kD})$ were produced by treating ferric iron saturated LF with trypsin or a combination of trypsin and chymotrypsin (results not shown).

Fragments of LF produced by in vitro trypsinization were detected by the ELISA method although trypsinization reduced the total amount of immunologically detectable LF by about $50 \%$ (Fig. 4). The results of the studies that were designed to ascertain whether LF fragments could be detected in the presence of intact LF were as follows. The mean $\pm \mathrm{SD}$ of the predicted amount of immunoreactive LF in the mixtures was $3.27 \pm 0.36$ $\mu \mathrm{g} / \mathrm{mL}$, whereas $2.88 \pm 0.66 \mu \mathrm{g} / \mathrm{mL}(p=0.05)$ was detected. Similar experimental results were obtained when trypsinized diferric LF was mixed with intact LF (results not shown).

\section{DISCUSSION}

LF, a single-chain glycoprotein, is composed of 703 amino acids arranged in two lobes, each of which has two domains and one site for binding $\mathrm{Fe}^{3+}(16)$. The N-lobe (residues 1-332) and the C-lobe (residues 344-703) are connected by a three-turn helix (residues 333-343) (16). When $\mathrm{Fe}^{3+}$ is bound, the protein be-

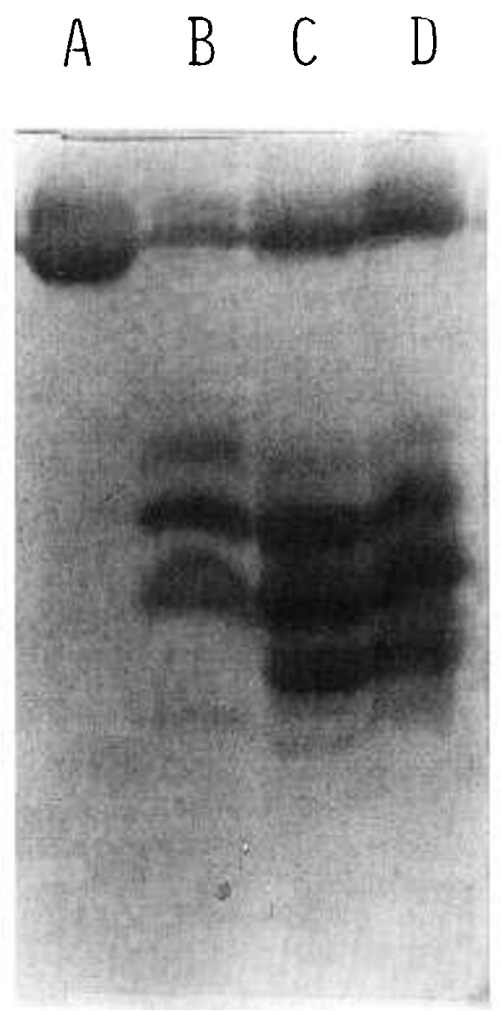

Fig. 3. A comparison of the fragments of apo-LF produced in vitro with trypsin and those found in stools and concentrated urine from an infant fed human milk. The lanes from the Western blot are as follows: $A$, human LF; $B$, human LF partially digested in vitro with trypsin; $C$, stool from an infant fed FHM; and $D$, urine from an infant fed FHM. Mol wt standards were also subjected to Western blotting but were not included in the illustration because of the low intensity of staining of the bands.

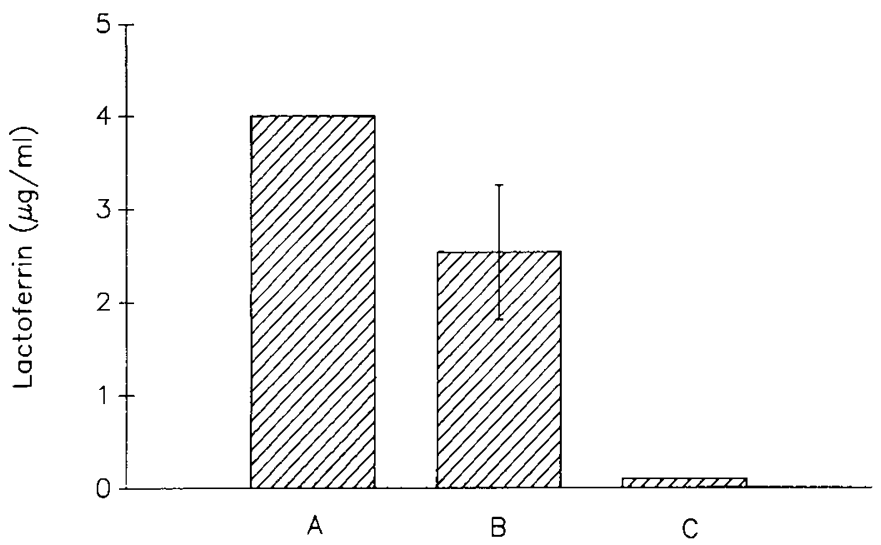

Fig. 4. The immunoreactivity of $\mathrm{LF}$ fragments produced in vitro by partial digestion with trypsin (substrate to enzyme ratio, 1:100). Immunoreactive LF was quantified in the following preparations by ELISA: $A$, purified LF $(4 \mu \mathrm{g} / \mathrm{mL}) ; B$, purified human $\mathrm{LF}(4 \mu \mathrm{g} / \mathrm{mL})$ treated with trypsin and then with a soybean antitrypsin; $C$, trypsin mixed with soybean antitrypsin (negative controls). No SD bars were included for the measurement of purified $\operatorname{LF}(A)$ or for the measurement of trypsin and the soybean antitrypsin $(C)$ because a predetermined amount of purified $\mathrm{LF}(4 \mu \mathrm{g} / \mathrm{mL})$ was used and no immunoreactive $\mathrm{LF}$ was detected in the negative controls $(C)$. No immunoreactive LF was detected with trypsin per se (data not shown).

comes more compact as the domains of each lobe close over the iron atom. Consequently, the protein becomes less susceptible to enzymatic digestion. Indeed, when diferric human LF is subjected to limited digestion with trypsin, two major fragments that correspond to the $\mathrm{N}$-lobe $(30 \mathrm{kD})$ and $\mathrm{C}$-lobe $(50 \mathrm{kD})$ are produced (17). Further, tryptic digestion of the N-lobe leads to an $18.5-\mathrm{kD}$ glycopeptide that includes the second domain of that lobe (18). The N-lobe of the molecule is pepsin sensitive, whereas the C-lobe remains intact after treatment with that enzyme (19). Many more molecular fragments are found, however, when apoLF is partially digested with trypsin or chymotrypsin (20).

In this study, we found that fragments, as well as the native form of LF, were excreted in the stools and urine of VLBW infants fed a FHM preparation. LF fragments have previously been demonstrated in stools of breast-fed infants by SDS-PAGE (21). A greater number of LF fragments was found in the current study, possibly because a more sensitive detection system, e.g. Western blotting, was used or because the maturity of subjects that were investigated was different. A $20-\mathrm{kD}$ fragment of LF that immunologically cross-reacts with bovine $\beta$-lactoglobulin has recently been found in human milk (22). That finding could not account for the several types of LF fragments found in the stools of our infants fed FHM. Furthermore, no LF fragments were detected in the human milk used in these feeding experiments. The discrepancy, however, may be due to differences in the specificities of the antisera used in the two studies. The fragments of LF in the stools of the VLBW infants most closely resembled those produced in vitro by partial digestion of apo-LF (20). Inasmuch as only intact LF was demonstrated in the FHM fed to the infants and most LF in human milk is in the apo form (23), the fragments of LF in the stools were most likely produced by partial digestion of apo-LF in the gastrointestinal tract of the recipient infants. It remains unclear, however, what proportion of the LF substrate originated from the FHM or was produced by the infant in response to human milk feedings $(10,12)$.

It was surprising that similar LF fragments were found in the urines of VLBW infants fed human milk. Inasmuch as proteolytic enzymes are not produced in the normal urinary tract and it was improbable that the urinary tract of each infant was colonized with protease-producing bacteria, it seems likely that the LF fragments originated in the gastrointestinal tract. It is of interest that somewhat smaller fragments were found in the stools 
possibly because of bacterial proteolysis in the lower intestinal tract of the recipient. It is also possible that some of the smaller fragments in the stools were generated because of in vitro proteolysis of the specimens. Furthermore, if the smaller fragments were produced in the intestinal tract and then were absorbed into the systemic circulation, they may have been cleared by the reticuloendothelial system before being filtered by the kidney. Finally, the way that the larger fragments of LF would be transported from the more proximal parts of the intestinal tract to the systemic circulation and hence to the urinary tract remains unclear.

Our study demonstrates that some epitopes of apo-LF are retained in fragments of that protein and the results suggest that the fragments along with intact LF may be detected in the excreta of VLBW infants fed human milk. The molecular structure of the fragments, the amounts of them in those excreta, and the retention of the biologic functions of intact LF (24-32) have not been established. Methods should be developed to distinguish quantitatively between the excretion of intact LF and its fragments and to separate each of the fragments for further molecular and biologic studies. This would further ascertain the fate and function of ingested LF or of LF produced in the alimentary tract of young infants.

A possible analogy to the occurrence of LF fragments in these infants is the generation of $\beta$-casomorphins in the gastrointestinal tract of newborn calves fed bovine casein (33). In vivo enzymatic cleavage of ingested casein produces biologically active peptides released from larger nutrient or immunologic proteins by partial proteolysis that may be absorbed into the systemic circulation and may have significant effects upon the recipient infant (34). That may be the case in respect to LF fragments in VLBW infants fed human milk.

Finally, it will be important to determine whether similar molecular fragments of LF occur in the excreta of mature, breastfed infants. Our preliminary findings indicate that is the case, but more extensive investigations will be required to definitively answer the question.

Acknowledgements. The authors thank Kimberly H. Palkowetz for technical assistance and Susan C. Kovacevich for assistance with this manuscript.

\section{REFERENCES}

1. Goldman AS, Goldblum RM 1985 Protective properties of human milk. In Walker WA, Watkins JB (eds) Nutrition in Pediatrics-Basic Sciences and Clinical Application. Little, Brown and Company, Boston, pp 819-828

2. Goldman AS, Goldblum RM 1989 Immunologic system in human milk: characteristics and effects. In: Lebenthal E (ed) Textbook of Gastroenterology and Nutrition in Infancy, 2nd ed. Raven Press, New York, pp 135-142

3. Roberts SA, Freed DLJ 1977 Neonatal IgA secretion enhanced by breast feeding. Lancet 2:1131

4. Gross SJ, Buckley RH 1980 IgA in saliva of breast-fed and bottle-fed infants. Lancet 2:543

5. Taylor CE, Toms GL 1984 Immunoglobulin concentrations in nasopharyngeal secretions. Arch Dis Child 59:48-53

6. Ostergaard PAA 1985 Serum and saliva Ig-levels in infants of non-atopic mothers fed breast milk or cow's milk-based formulas. Acta Paediatr Scand 74:555-559

7. Gleeson M, Cripps AW, Clancy RL, Hensley MJ, Dobson AJ, Firman DW 1986 Breast feeding conditions a differential developmental pattern of mu- cosal immunity. Clin Exp Immunol 66:216-222

8. Stephens S 1986 Development of secretory immunity in breast fed and bottle fed infants. Arch Dis Child 61:263-269

9. Aldred MJ, Vaughn AG, Yuill SJ, Wade WG, Walker DM 1986 Persistence of IgA in neonatal saliva following breast feeding. Early Human Dev 14:274276

10. Schanler RJ, Goldblum RM, Garza C, Goldman AS 1986 Enhanced fecal excretion of selected immune factors in very low birth weight infants fed fortified human milk. Pediatr Res 20:711-715

11. Prentice A 1987 Breast feeding increases concentrations of $\operatorname{IgA}$ in infants urine. Arch Dis Child 62:792-795

12. Goldblum RM, Schanler RJ, Garza C, Goldman AS 1989 Human milk feeding enhances the urinary excretion of immunologic factors in low birth weight infants. Pediatr Res 25:184-188

13. Schanler RJ, Garza C, Nichols BL 1985 Fortified mothers' milk for very low birthweight infants: Results of growth and nutrient balance studies. J Pediatr $107: 437-438$

14. Symington J 1984 Electrophoretic transfer of proteins from two dimensional gels to sheets and their detection. In: Celis JE, Bravo R (eds) Two Dimensional Gel Electrophoresis of Proteins: Methods and Applications. Academic Press, New York, pp 3-36

15. Chung MC-M 1985 A specific iron stain for iron-binding proteins in polyacrylamide gels: application to transferrin and lactoferrin. Anal Biochem 148:498-502

16. Anderson BF, Baker HM, Dodson EJ, Norris GE, Rumball SV, Waters JM Baker EN 1987 Structure of human lactoferrin at 3.2- $\AA$ resolution. Proc Natl Acad Sci USA 84:1769-1773

17. Legrand D, Mazurier J, Aubert J-P, Loucheux-Lefebvre M-H, Montreuil J, Spik G 1986 Evidence for interactions between the $30 \mathrm{kD} \mathrm{N}$-and $50 \mathrm{kD}$ Cterminal tryptic fragments of human translactoferrin. Biochem J 236:839844

18. Montreuil J, Mazurier J, Legrand D, Spik G 1985 Human lactotransferrin: structure and function. In: Spik G, Montreuil J, Crichton RR, Mazurier J (eds) Proteins of Iron Storage and Transport. Elsevier Science Publishers B.V. (Biomedical Division), Amsterdam, pp 25-38

19. Line WF, Sly DA, Bezkorovainy A 1976 Limited cleavage of human lactoferrin with pepsin. Int J Biochem 7:203-208

20. Brines RD, Brock JH 1983 The effect of trypsin and chymotrypsin on the in vitro antimicrobial and iron-binding properties of lactoferrin in human milk and bovine colostrum. Biochim Biophys Acta 759:229-235

21. Spik G, Brunet B, Mazurier-Dehaine C, Fontaine G, Montreuil J 1982 Characterization and properties of the human and bovine lactotransferrins extracted from the faeces of newborn infants. Acta Paediatr Scand 71:979-985

22. Monte JC, Mermoud A-F, Jolles P 1989 Anti-bovine $\beta$-lactoglobulin antibodies react with a human lactoferrin fragment and bovine $\beta$-lactoglobulin present in human milk. Experientia 45:178-180

23. Fransson GB, Lönnerdal B 1980 Iron in human milk. J Pediatr 96:380-384

24. Montreuil J, Torrelat J 1960 Preparation et proprietes de la lactosiderophiline (lactotransferrine) du lait de femme. Biochim Biophys Acta 45:413-421

25. Johansson B 1960 Isolation of an iron-containing red protein from human milk. Acta Chem Scand 14:510-512

26. Cox MT, Mazurier J 1979 Iron binding proteins and influx of iron across the duodenal brush border. Evidence for specific lactotransferrin receptors in human intestine. Biochem Biophys Acta 588:120-128

27. Mazurier J, Montreuil J, Spik G 1985 Visualization of lactotransferrin brush border receptors by ligand-blotting. Biochim Biophys Acta 821:453-460

28. Masson PL, Hereman JF 1966 Studies on lactoferrin, the iron binding protein of secretions. Protides Biol Fluids 14:115-124

29. Spik G, Cheron A, Montreuil J, Dolby JM 1978 Bacteriostasis of a milksensitive strain of Escherichia coli by immunoglobulins and iron-binding proteins in association. Immunology 35:663-671

30. Stuart J, Norrell S, Harrington JP 1984 Kinetic effect of human lactoferrin on the growth of Escherichia coli. J Biochem 16:1043-1047

31. Nichols BL, McKee KS, Henry JF, Putnam M 1987 Human lactoferrin stimulates thymidine incorporation into DNA of rat crypt cells. Pediatr Res 21:563-567

32. Goldman AS, Thorpe LW, Goldblum RM, Hanson LA 1986 Anti-inflammatory properties of human milk. Acta Paediatr Scand 75:689-695

33. Umbach M, Teschemacher H, Praetorius K, Hirschhauser R, Bostedt H 1985 Demonstration of a $\beta$-casomorphin immunoreactive material in the plasma of newborn calves after milk intake. Reg Peptides 12:223-230

34. Teschemacher H $1987 \beta$-Casomorphins: do they have physiological significance? In: Goldman AS, Atkinson SA, Hanson LA (eds) Human Lactation 3-The Effects of Human Milk on the Recipient Infant. Plenum Press, New York, pp 213-225 